\title{
Oxysterols: Side Health Effects
}

\author{
Barrientos Salcedo Carolina, Sosa Rueda Javier and Soto Rodríguez Ida* \\ Bioanalysis Faculty, Universidad Veracruzana, Mexico \\ *Corresponding author: Soto Rodríguez Ida, Bioanalysis Faculty, Universidad Veracruzana, Veracruzana, Mexico
}

\begin{tabular}{|c|c|}
\hline ARTICLE INFO & ABSTRACT \\
\hline Received: March 09, 2020 & Some of the food in our diet contain lipids that can cause health damage. This is the \\
\hline Published: 仹 March 13, 2020 & $\begin{array}{l}\text { case of oxysterols, which are formed when processing high cholesterol foods. Therefore, } \\
\text { oxysterols might be related to appearance of chronic degenerative diseases (obesity, }\end{array}$ \\
\hline
\end{tabular}

J, Soto Rodríguez I Oxysterols: Side Health Effects. Biomed J Sci \& Tech Res 26(4)2020. BJSTR. MS.ID.004377.
Keywords: Lipids; Oxysterols; Chronic Diseases

\section{Opinion}

Recent investigations have stablished a direct association between food fat content, dyslipidemia and chronic degenerative diseases. However, lipids such as oxysterols in our diet may develop health issues because of its processing. While cholesterol is an essential compound for cellular membrane, and precursor of bile acids, vitamin D and hormones, oxysterols play a role in the pathogenesis of diseases like atherosclerosis, non-alcoholic fatty liver disease, diabetes and Alzheimer [1]. Animal source foods with high cholesterol levels are susceptible to the formation of oxysterols from this compound as a result of physical and chemical changes in its elaboration: high and low temperatures; extended periods of light and oxygen exposures; pH modifications; undefined storage hours; and any changes that break cholesterol's double bond and eases the formation of different oxysterols (Figure 1). If we analyze Mexican gastronomy, around $60 \%$ of the diet consists of processed foods, usually known as «antojitos» and «traditional food», with a notable predomination of meat and fried or frozen seafood which are commonly exposed to sunlight.

As an example, «chicharrón» is made of pork skin fried in big oil containers and then conserved but exposed to light during its commercialization all around the country. Sunlight is also used by distributors and fishermen on the coast regions to dry shrimp and other kind of seafood. Meanwhile, on the north territory, dried meat «machaca» is frequently consumed, but the industrial processing exposes meat pieces to temperature changes to eliminate water content, and considerable quantities of salt are added before being vacuum packed. Recent studies of this products [2] have demonstrated presence of oxysterols on them, and the chromatographic analysis not only identified many types but also content differences. Previous research shows how some kinds of oxysterols affect health more than others. So, 7-ketocholesterol and 25-hydroxycholesterol (all identified on our three previous examples) are cytotoxic because they inhibit the activity of some indispensable enzymes for muscular cells division located in arteries such as the aorta. These particularities of popular Mexican food bring us interrogations about how and what human organs are affected by oxysterols: are they strongly associated to chronic degenerative diseases presence? Laboratory animals stand as a useful way to get answers.

Investigators may administrate certain oxysterols quantities, realize blood tests and obtain clinical diagnoses; they can also perform histological analyzes on the organs involved. To increase the available information about cytotoxic damage caused by some oxysterols, in 2009 an experiment was performed on laboratory rats with certain doses of an oxysterol's mixture [3]. The results confirmed atherogenic damage and showed how the liver and kidneys can be affected by the intake of these molecules. The effects on the organism begin through an imbalance in serum cholesterol and triglyceride levels, a phenomenon like the observed in diets rich in carbohydrates and saturated fats. In response to 
this imbalance, fat deposits in the arteries become more noticeable until the formation of atheroma that obstruct blood circulation. The experiment also concluded that oxysterols don't facilitate an ideal triglyceride metabolism in the liver, which results on the nonalcoholic disease determined by the accumulation of fatty acids in the cytoplasm of hepatocytes, which affects multiple metabolic functions: glucose regulation; protein making; and insulin production, essential for the glucose metabolization. Kidneys can be also altered by oxysterols.
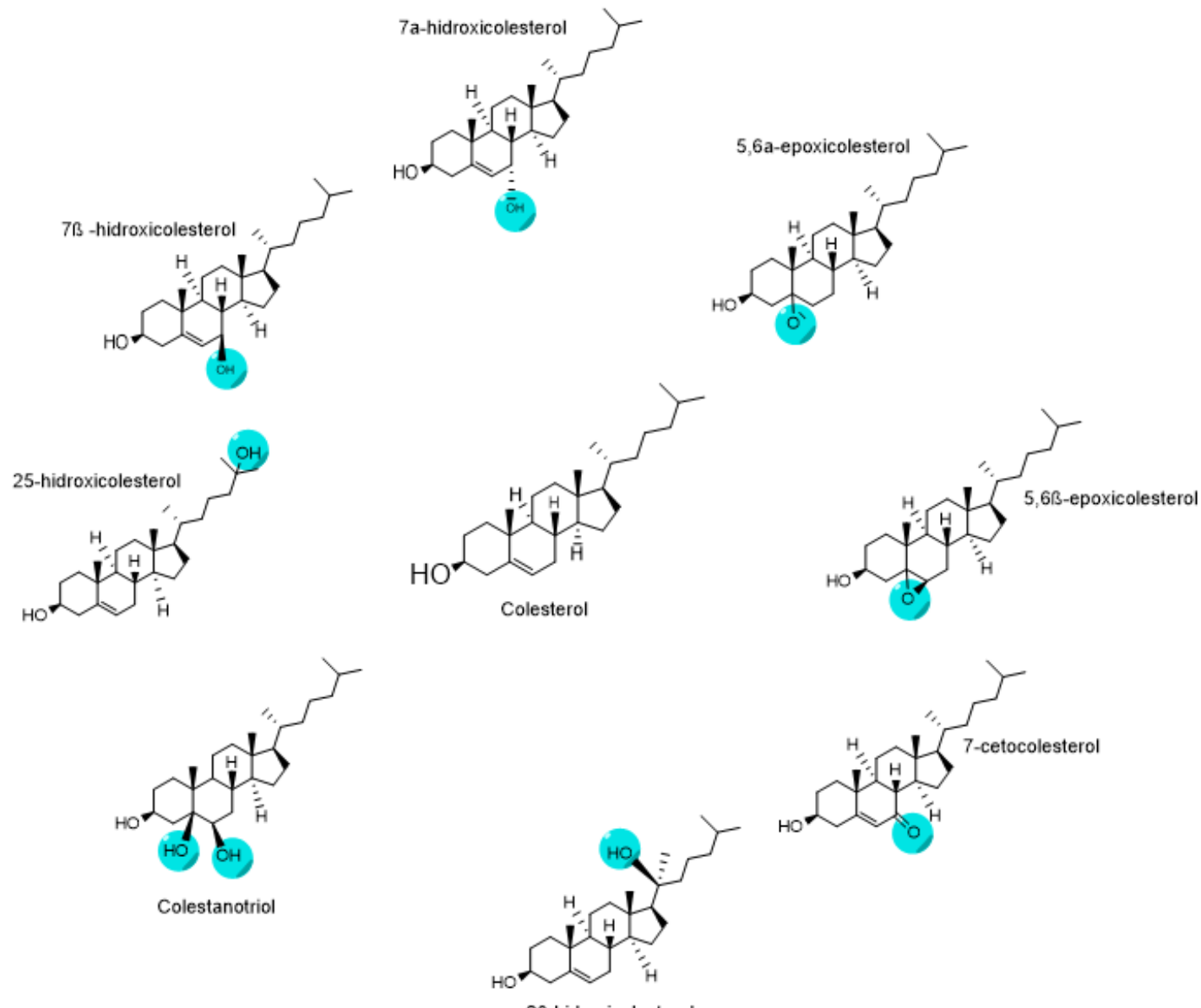

Colestanotriol

20-hidroxicolesterol

Figure 1: Chemical structure of cholesterol and oxysterols.

The experiment on rats showed an increase of the activation of cells that generate inflammatory processes in the nephron, followed by tissue atrophy and renal insufficiency. According to the Organisation for Economic Co-operation and Development (OECD) [4], Mexico stands as one of the nations with higher rates of obesity in adults and occupies the second place in childhood obesity. Despite the implementation of public policies to control overweight and obesity (campaigns pro healthy food; nutrition labeling; regulation of media advertising), there hasn't been real success to eradicate them at all. But this situation has motivated new investigations seeking for therapeutic and preventive strategies to combat obesity issues. As a reminder, the origin of obesity is essentially an imbalance in energy metabolism. Human body keeps a system for the storage of extra energy: white adipose tissue and its specialized cells that collect metabolic energy in the form of triglycerides. Adipose tissue emits a set of molecules called adipokines with influence over the whole organism. When adipose tissue atrophies, adipokine triggers pro inflammatory commands over local and remote zones that may cause type II diabetes, nonalcoholic fatty liver disease and obesity [5].

It is known that some biomarkers (independent from cholesterol) and blood pressure regulators such as tumor necrosis factor- $\alpha$ y la resistin are indicators of inflammatory events in atherosclerosis. But other less studied analyses of clinical diagnosis reveal signs of cardiovascular risk too [6]. For example, the levels of high-sensitivity C-reactive protein, tumor necrosis factor alpha and resistin in plasma are altered, as demonstrated by subjecting laboratory animals to an oxysterols diet for eight weeks. Once again, the results confirmed the alterations that occur in patients with dyslipidemias, type II diabetes and obesity like increased cholesterol levels, triglycerides and blood pressure. In addition, it showed raised levels of resistin and high-sensitivity C-reactive protein, what establish them as good markers of cardiovascular risk. 
Damage to the organs involved in metabolism of oxysterols should be known to the competent authorities. Although it's not possible to prevent their formation during the industrialization processes of animal source food, it is critical to take regulatory measures that identify minimum levels of oxysterols because population's health is being compromised. These molecules should be considered a factor of risk just like glucose and serum cholesterol levels that lead to chronic degenerative diseases, which are the second cause -following infectious diseases-of death in our country.

\section{References}

1. Giuseppe Poli, Barbara Sottero, Simona Gargiulo, Gabriella Leonarduzzi (2009) Cholesterol oxidation products in the vascular remodeling due to atherosclerosis. Molecular Aspects of Medicine 30(3): 180-189.

2. Soto Rodríguez I, Campillo VPJ, Ortega Martínez J, Rodríguez Estrada, María T, et al. (2008) Cholesterol oxidation in traditional mexican dried

\section{ISSN: 2574-1241}

DOI: $10.26717 /$ BJSTR.2020.26.004377

Fitim Arifi. Biomed J Sci \& Tech Res

(C) (1) This work is licensed under Creative

Submission Link: https://biomedres.us/submit-manuscript.php and deep-fried food products. Journal of Food Composition and Analysis 21(6): 489-495.

3. Soto Rodríguez I, Campillo VPJ, Ortega Martínez, Alexander Aguilera A, María T, et al. (2009) Biochemical and histopathological effects of dietary oxidized cholesterol in rats. J Appl Tox 29(8): 715-723.

4. (2017) OCDE. Obesity Update.

5. Soto Rodríguez I, Quintana Castro R, Cano Martínez CA, Aguirre Maldonado I, Granados Echegoyen C, et al. (2017) Morinda citrifolia (Noni) changes the expression of AdipoR2 mRNA in hepatic tissue of rats with nonalcoholic fatty liver disease (NAFLD). Journal of Pharmacognosy and Phytochemistry 6(1): 120-125.

6. Soto Rodríguez I, Alexander Aguilera A, Zamudio Pérez A, Camara Contreras M, Hernández Díaz G, et a l. (2012) Alteration of Some Inflammatory Biomarkers by Dietary Oxysterols in Rats. Inflammation 35(4): 1302-1307.

$\begin{array}{ll}\text { BIOMEDICAL } & \text { Assets of Publishing with us } \\ \text { RESEARCHES } & \text { - Global archiving of articles } \\ \text { - Immediate, unrestricted online access } & \text { - Rigorous Peer Review Process } \\ & \text { - Authors Retain Copyrights } \\ & \text { https://biomedres.us/ }\end{array}$

